\title{
Études rabelaisiennes, tome LIV
}

\section{Sabine Lardon}

\section{(2) OpenEdition}

\section{Journals}

\section{Édition électronique}

URL : http://journals.openedition.org/studifrancesi/10536

DOI : 10.4000/studifrancesi. 10536

ISSN : 2427-5856

\section{Éditeur}

Rosenberg \& Sellier

\section{Édition imprimée}

Date de publication : 1 décembre 2017

Pagination : 536

ISSN : 0039-2944

\section{Référence électronique}

Sabine Lardon, «Études rabelaisiennes, tome LIV », Studi Francesi [En ligne], 183 (LXI | III) | 2017, mis en ligne le 01 février 2018, consulté le 27 janvier 2021. URL : http://journals.openedition.org/ studifrancesi/10536 ; DOI : https://doi.org/10.4000/studifrancesi.10536

\section{Ce document a été généré automatiquement le 27 janvier 2021.}

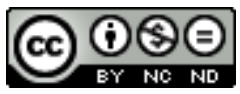

Studi Francesi è distribuita con Licenza Creative Commons Attribuzione - Non commerciale - Non opere derivate 4.0 Internazionale. 


\title{
Études rabelaisiennes, tome LIV
}

\author{
Sabine Lardon
}

\section{RÉFÉRENCE}

Études rabelaisiennes, tome LIV, Genève, Librairie Droz, 2015, 133 pp.

1 Tristan VIGLiano (Le pantagruélisme est-il un paganisme? Rabelais et l'amour des ennemis, pp. 7-51) interroge, de manière approfondie, la notion de charité à travers ce qui distingue l'amour évangélique du pantagruélisme, à savoir la difficulté, dans l'œuvre, de penser un amour dirigé vers l'ennemi. L'approche rabelaisienne est confrontée à celle des Écritures et des Évangéliques (Érasme, Lefèvre d'Étaples, Marguerite de Navarre) afin d'en dégager la spécificité: «Rabelais appartient à un milieu évangélique, utilise un vocabulaire évangélique, se réclame d'une foi évangélique», pour autant «le pantagruélisme, en tant qu'il a ses exclusives et qu'il les revendique, n'est pas une norme évangélique» et ne saurait se poser en catéchisme (p. 51). Partant de la place du lieu commun dans la méthode d'éducation érasmienne (De ratione Studii), Éric M. MACPHAIL étudie la façon dont Rabelais utilise le lieu commun afin de l'intégrer à la fiction (Rabelais and the Circulation of Commonplaces in Renaissance Humanism, pp. 53-69). Raphaël CAPPELLEN (Rabelais entre bibliophilie et lecture érudite: sur un exemplaire du Tiers Livre de 1552, pp.71-95) étudie la réception de Rabelais à partir des annotations manuscrites sur un exemplaire du Tiers Livre conservé à l'Université de Virginie, en s'intéressant aux notes de deux de ses nombreux possesseurs: Guy Patin, le plus ancien identifié, et un lecteur anonyme, qu'on lui pense antérieur, dont les annotations s'apparentent à de véritables commentaires érudits, leur auteur corrigeant les scories de l'édition, précisant des étymologies, en s'intéressant tout particulièrement aux emprunts au grec, élucidant les sources et dégageant, à partir de leur récurrence, des constantes thématiques dans l'œuvre.

2 Jonathan PATTERSON (Rabelais's Uncommon Villains: A Reinterpretation of Quart Livre 45-7, pp. 97-113) s'intéresse à la figure du «villain», partant d'un parcours de l'ensemble de l'œuvre pour se concentrer ensuite sur les chapitres 45-46, puis 47 du Quart Livre. 
François ROUGET (Avantage Saint-Gelais: retour sur l'attribution de l'Enigme en prophetie (Gargantua, chap. 58), pp. 115-132) reconsidère la question problématique de l'attribution à Mellin de Saint-Gelais ou à Rabelais de l'«Enigme trouvé es fondemens de l'abbaye des Thelemites» (chapitre 56 dans l'édition originale de Gargantua), devenue l'«Enigme en forme de prophetie» (chapitre 58 dans l'édition de 1542). Après avoir rappelé les arguments des partisans de l'une ou de l'autre position, F. Rouget propose un réexamen des données historiques et matérielles, afin de défendre l'hypothèse d'une collaboration entre les deux auteurs, impliquant donc la contribution de Saint-Gelais.

3 Les Études rabelaisiennes nous proposent donc, une fois de plus, avec ce tome LIV, de très riches et intéressantes études qui balaient différents aspects de la question rabelaisienne: nuance de la pensée, procédés d'écriture, problèmes d'attribution et questions de réception à travers des articles de grande qualité. 